\title{
Infographic. Golf spectating and health
}

Andrew Murray, ${ }^{1,2}$ Hilary Scott ${ }^{1,3}$ Daryll Archibald, ${ }^{4}$ Kieran Turner, ${ }^{1}$ Steffan Arthur Griffin, ${ }^{5}$ Chloe Schiphorst, ${ }^{1}$ Roger Hawkes, ${ }^{6}$ Paul Kelly, ${ }^{1,7}$ Liz Grant, ${ }^{8}$ Nanette Mutrie ${ }^{1,7}$

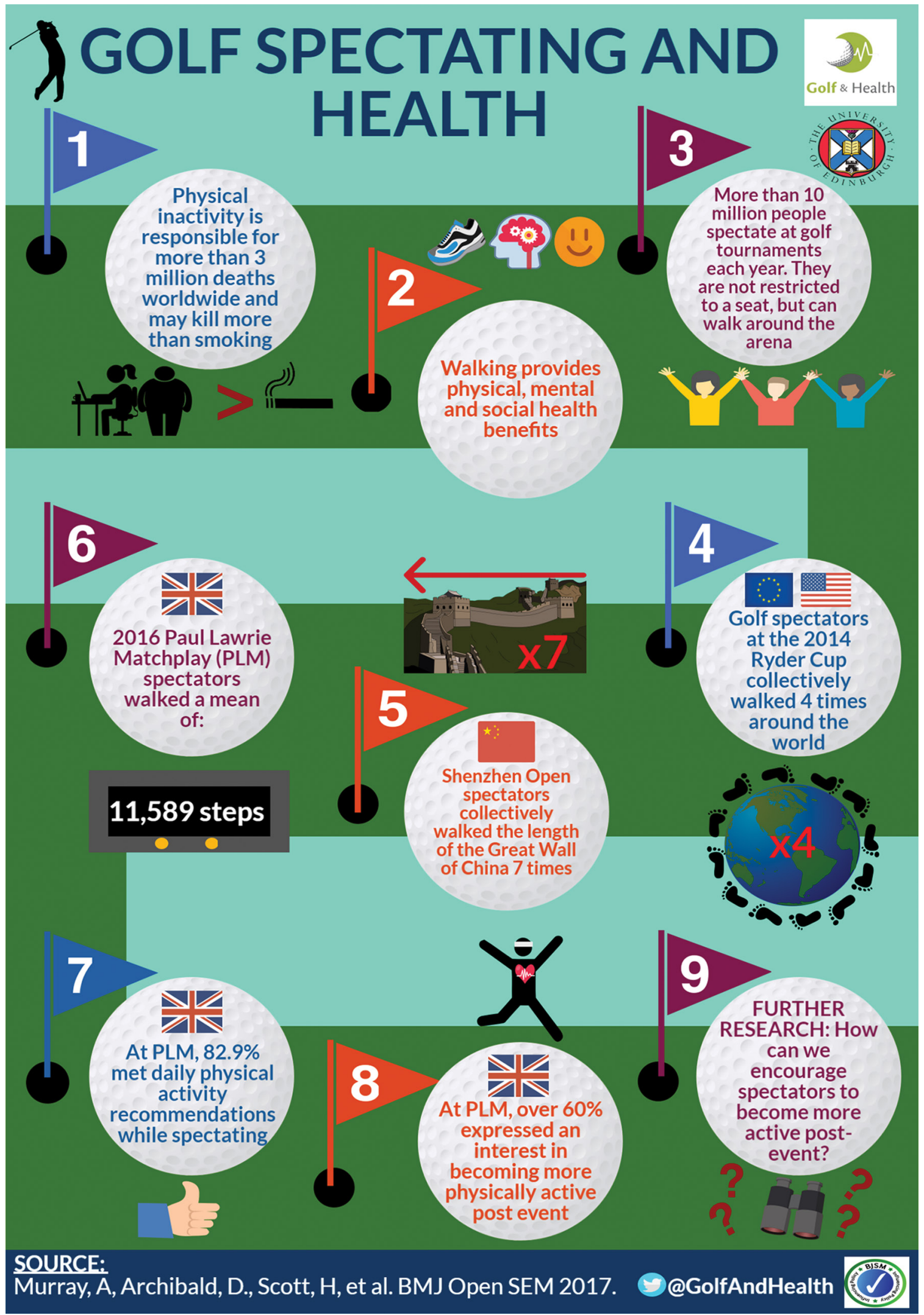




\section{Infographics}

${ }^{1}$ Physical Activity for Health Research Centre, University of Edinburgh, Edinburgh, UK

${ }^{2}$ Sport and Exercise, University of Edinburgh, Edinburgh, UK

${ }^{3}$ Faculty of Health and Social Care, Robert Gordon University, Aberdeen, UK

${ }^{4}$ Scottish Collaboration for Public Health Research and Policy, University of Edinburgh, Edinburgh, UK

${ }^{5}$ College of Medical and Dental Sciences, University of Birmingham, Birmingham, UK

${ }^{6}$ European Tour, European Tour Performance Institute, Viginia Water, UK

'Moray House School of Education, Institute of Sport Physical Education and Health Sciences, University of Edinburgh, Edinburgh, UK

${ }^{8}$ Global Public Health, University of Edinburgh, Edinburgh, UK

Acknowledgements The authors wish to thank Paths for All, the European Tour Golf, and 4sports for their input and collaboration at the Paul Lawrie Matchplay tournament. Tournament host Paul Lawrie, as a player provided leadership in highlighting potential opportunities for players to promote physical activity amongst spectators. We thank Jack Luscombe for his assistance with data collection.

Competing interests This research was part funded by an unrestricted grant for the World Golf Foundation, who committed to publishing results whatever the findings. AM and RAH work as clinicians for the European Tour Golf.

Patient consent Obtained.

Ethics approval Ethical approval was granted by the Moray House School of Education Ethics Committee, University of Edinburgh.

Provenance and peer review Not commissioned; externally peer reviewed.

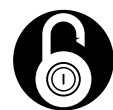

\section{OPEN ACCESS}

Open Access This is an Open Access article distributed in accordance with the terms of the Creative Commons Attribution (CC BY 4.0) license, which permits others to distribute, remix, adapt and build upon this work, for commercial use, provided the original work is properly cited. See: http:// creativecommons.org/licenses/by/4.0/

(c) Article author(s) (or their employer(s) unless otherwise stated in the text of the article) 2018. All rights reserved. No commercial use is permitted unless otherwise expressly granted.

D) Check for updates

To cite Murray A, Scott $\mathrm{H}$, Archibald D, et al Br J Sports Med 2018;52:415-416.

Received 15 April 2017

Revised 5 June 2017

Accepted 8 June 2017

Published Online First 31 July 2017

Br J Sports Med 2018:52:415-416.

doi:10.1136/bjsports-2017-097933 